\title{
The Strategic Use of Bankruptcy Prediction Models: An Aid to Executive Decision Making
}

\author{
Sukumar C. Debnath \\ College of Business Administration \\ Prairie View A \& M University \\ Prairie View, Texas \\ Aubrey R. Fowler, Jr. \\ College of Business Administration \\ Nicholls State University \\ Thibodaux, Louisiana \\ Stephen C. Bushardt \\ College of Business Administration \\ University of Southern Mississippi \\ Hattiesburg, Mississippi
}

The last decade has seen a flood of business failures in the United States. These failures, ranging from the smallest of entrepreneurial firms to corporate giants, have had a significant impact on the general well being of the U.S. economy, have led to the loss of thousands of jobs, and have cost investors and creditors millions of dollars. In addition the news media give reports, almost daily, of other firms that are exhibiting financial difficulty and facing the imminent possibility of insolvency and the need to seek protection under bankruptcy law. Firms in such diverse industries as airlines, meat packing, and computers all appear to be on the brink of seeking reorganization under Chapter 11 or liquidation under Chapter 7 of the federal bankruptcy code.

These business failures are frequently offered as a major criticism of a capitalistic system and the supposed "crisis" created by them as justification for changing to a more controlled economy. However, the fact of bankruptcy and the economic losses associated with it are actually a control mechanism that properly removes economic units that are incapable of effectively competing thereby weeding out the inefficient and rewarding those that are able to meet the needs of the market and properly manage their resources. In effect, bankruptcy is one of the expenses to an economy that allows for both the acceptance of risk and the rewards associated with success.

Therefore, bankruptcy should not be viewed solely from the viewpoint of the firm involved and those associated with it. Furthermore, it should be noted that bankruptcy serves a positive function when eliminating inefficient

Journal of Business Strategies, Volume 4, Number 2 (Fall 1987) 
competitors as a result of their own financial weakness and that under today's bankruptcy law the act of seeking protection under Chapter 11 may relate to issues other than immediate threat of insolvency. For instance, firms may use bankruptcy protection to abrogate a collective bargaining contract. However, given the economic hardship created by business failures, it seems obvious that any tool or technique that could help avoid such failures would be a valuable aid to business decision makers. One such useful technique would be an early identification of those firms at risk of encountering financial difficulty. Over the years a number of efforts have been made to devise analytical models useful in predicting corporate financial failure. These efforts have led to the creation of several models with a high degree of predictive ability which are able to detect potential failure as early as three to five years in advance.

\section{Purpose}

Since the future condition of a company with respect to its financial well being can be very important to a variety of parties (i.e., executives, investors, employees, or regulatory agencies), an ability to accurately predict financial problems can have a significant impact on decisions regarding their involvement with companies showing a potential for failure. For example, executives of such companies would have more time in which to determine the causes leading to failure and work to correct them. Potential investors would also have a better assessment of the risk they undertake.

With financial failure a growing problem in the U.S. ([3], [5], [20]) it would seem that the availability of models capable of predicting such failure is increasingly important. Their use will assist in the recognition of potential problems, in helping to identify the underlying causes of those problems, and as a starting point for the development of corrective action. With this in mind the purpose of this paper is to:

1. review the bankruptcy prediction models (BPM's);

2. discuss the use of the BPM's for internal analysis and problem solving;

3. discuss the use of BPM's as a tool for evaluating firms as potential acquisition targets; and

4. briefly identify other possible applications of BPM's.

The essential thrust of the paper will be to evaluate the strategic value of BPM's as an important tool in executive decision making.

\section{Why Businesses Fail}

There are a variety of reasons why businesses fail. However, it is generally accepted that the fundamental underlying cause of failure is poor management. This position is supported in the literature $([6],[7],[11])$ and has been recognized for a considerable length of time. Among the elements of poor management contributing to failure are: 
1. faulty decision making,

2. poor allocation of resources,

3. failure to correct operating inefficiencies,

4. poor choice of products and marketing strategy,

5. poor financial management, and

6. inadequate planning.

There are, of course, other factors, external to the organization, that can lead to failure. In particular, the overall status of the national economy and the competitive situation are important contributors to failure ([3], [6], [7]). Other contributing factors include:

1. governmental regulation,

2. technological innovation,

3. natural disasters,

4. labor problems, and

5. changes in cultural/social values.

When failure occurs it is frequently a shock to most who are associated with the firm involved. Particularly when large firms declare bankruptcy the event receives national attention and the public at large is led to wonder how such rich and powerful organizations could fail. There is a tendency to look for singular causes of a disastrous nature when the reality is that financial collapse is seldom sudden and rarely from a single cause [20].

The above observation serves as the foundation for the development of models to predict failure. If those factors that are symptomatic of failure and which show those symptoms in advance can be identified, the failure may be predicted and, with proper management in the interim, avoided. Therefore, the BPM's are tools that may improve poor management by identifying in a timely manner potential problems and give some indication of their underlying causes.

\section{A Review of Bankruptcy Prediction Models}

Since the early 1900 's, researchers have sought ways of identifying companies that are developing a potential for encountering significant financial problems. These research efforts have resulted in the development of a number of empirically derived bankruptcy prediction models that offer sufficient predictive ability to be of assistance to managers involved in strategic planning. 
Most of the earlier models ([8], [9], [12], [15], [19], [22]) relied on comparative ratio analysis as the basis for their predictions. In them, researchers compared a variety of common financial ratios of failed firms to matching nonfailed firms or industry averages as a basis for determining critical values for those ratios. Firms that failed to meet those critical values were determined to be in jeopardy of severe financial consequences.

As nseful models, these early efforts suffered from a major problem in that each offered several ratios as a basis for comparison. Unfortunately, these models failed to provide a single, comprehensive basis for determining potential financial problems due to contradictory results. This issue has been addressed in more recent years through the use of discriminant analysis as a means of identifying significant predictor variables (still financial ratios) and their relative importance and interrelationship through the development of a discriminant function to predict financial well being. Using these functions a firm or other user of the model computes a score based on the values of the significant variables, model coefficients and constants and compares this score with a single critical value for determining risk of severe financial difficulty (see [1], [4], [10], [18], and [21]). These models offer a high degree of predictive ability, ranging in accuracy from a high of $99 \%$ for a one year prediction [21] to a high of $78 \%$ for a five year prediction $[10]$.

In spite of this predictive ability the use of BPM's has been criticized. A major problem associated with the models is their inconsistency in selecting significant variables from essentially similar sets of financial ratios. This makes it difficult to determine which model to use and suggests that the accuracy of a given model may be dependent on the general economic environment in which it is applied [14].

A second important criticism involves the limited theoretical basis for much of the empirical work leading to the development of the models and their ignoring of causal relationships between the financial ratios and failure [17]. In essence, the financial ratios serve as symptoms of potential failure but do not indicate the causes of such failure. For instance, a retail firm that shows a deterioration in its average collection period has a problem, but the ratio itself simply indicates the existence of the problem, not the underlying cause. The deterioration may result from overly liberal credit terms, improper billing and record keeping procedures, or a shift in the economic well-being of the customer base. If the change in the ratio is seen as indicating an important problem, a firm's objective might be to improve that ratio and to accomplish that it must identify the underlying reason for the unacceptable ratio and concentrate on correcting it. Therefore, the BPM's are diagnostic tools identifying problems rather than prescriptive tools for avoiding bankruptcy. An additional criticism is that firms encountering financial problems may delay in reporting financial data which may create accuracy problems in predicting pending failure based on recent operations [13]. 


\section{A Bankruptcy Prediction Model in Use}

Given these models and criticisms of them, a brief overview of one in operation might benefit the reader. In a study reported in 1983 [5], the Zeta model was compared with the Relative Financial Strength System published as part of the Value Line Investment Survey. In the study the two models were found to be comparable in their ability to predict financial disaster for business firms. Using the Zeta model 68 of 73 major bankruptcies occurring during the years 1977 to 1982 were predicted based on their Zeta Score. Table 1 , as exerted from Altman and Spivack ([5], p. 63), shows the total results of the study and Table 2 shows examples of selected companies.

Table 1

Time of Financial Statement In

Periods Before Bankruptcy

\begin{tabular}{|lrrrrr|}
\hline \multicolumn{1}{|c|}{ Rumberults } & $\mathbf{0}$ & $\mathbf{1}$ & $\mathbf{2}$ & $\mathbf{3}$ & $\mathbf{4}$ \\
\hline Companies Correctly & & & & & \\
Classified & 68 & 62 & 47 & 37 & $\mathbf{3 4}$ \\
Companies Incorrectly & & & & & \\
Classified & 5 & 9 & 19 & 23 & $\mathbf{2 3}$ \\
Total Companies & $\mathbf{7 3}$ & $\mathbf{7 1}$ & 66 & 60 & 57 \\
Percent Correct & 93 & 87 & $\mathbf{7 1}$ & 62 & 60 \\
Percent Incorrect & $\mathbf{7}$ & 13 & 29 & 38 & 40 \\
\hline Average Score & -4.72 & -2.62 & -1.44 & -0.79 & -0.53 \\
\hline
\end{tabular}

Table 2

Examples and Results of Zeta Score Use, Selected Companies

\begin{tabular}{|lrrc|}
\hline \multicolumn{1}{|c}{ Company } & $\begin{array}{c}\text { Bankruptcy } \\
\text { Date }\end{array}$ & $\begin{array}{c}\text { Zeta } \\
\text { Score }\end{array}$ & $\begin{array}{c}\text { Number of Months } \\
\text { with } \\
\text { Negative Score }\end{array}$ \\
\hline A M International & $4-14-82$ & -4.6 & 20 \\
Allied Artists & $4-5-79$ & -7.07 & 120 \\
Bobbie Brooks & $1-17-82$ & -1.98 & 103 \\
Braniff Airlines & $5-13-82$ & -3.40 & 28 \\
Lionel & $2-82$ & -15.79 & 64 \\
Mansfield Tire & $10-79$ & -8.20 & 22 \\
Sambo's & $11-81$ & -3.51 & 35 \\
Seatrain Lines & $2-11-81$ & -2.41 & 115 \\
White Motor Co. & $9-4-80$ & -1.41 & 116 \\
Wicker Cos. & $4-25-82$ & -0.92 & 15 \\
\hline
\end{tabular}


For all of the companies covered in the study the average lead time by which the Zeta score predicted bankruptcy was 53 months. Furthermore, as shown by average scores and pointed out by the authors, the trend toward greater negativity appears to be as important in predicting bankruptcy as does the negative score itself.

\section{Bankruptcy Prediction Models for Internal Analysis}

In recent years, the concept and practice of strategic management has taken on greater importance for business organizations. A fundamental aspect of strategic management is the ability to forecast future events as a basis for current decision making. Therefore, the ability to predict an event of such importance as bankruptcy has significant value to the strategic decision maker. In a strategic sense, survival is one of the fundamental objectives of most business organizations. Bankruptcy prediction thus acquires an even greater importance, since financial insolvency is one of the strongest possible threats to continued existence. The need, then, is to be aware of BPM's and to be able to use the information available from them in a manner conducive to avoiding the developing problem.

Fundamental to their use is to remember that the BPM's are diagnostic rather than prescriptive. They indicate that something needs to be done but not what to do. It is the responsibility of the strategic manager to utilize the BPM results to first assess the causes of the pending problem and then to determine how best to avoid that problem. The models' use of financial ratios as the basis for their predictions provide a warning signal and some indication of where imbalance in the firm's operations exists. For instance, a firm using the Zeta-Model [4] and calculating a Zeta score indicative of pending bankruptcy can look at the ratios comprising the discriminant function and compare them with industry standards. Those that are substandard provide a basis for determining why the problem is developing. Using the Zeta model the ratio of retained earnings to total assets is the most important predictor of trouble. Therefore if the $\mathrm{RE} / \mathrm{TA}$ ratio for a firm is substantially less than for other firms, particularly those in its industry, the firm has an indication that it relies too heavily on external sources of funds and that it suffers from either or both of substandard profitability, thereby reducing the ability to retain earnings, or overly generous dividend policies, thereby satisfying short term stockholder needs for income while jeopardizing their long term interests.

Other examples using other ratios or other models can be given. However, the important issue is that the information is potentially available, not the specific details of its use. Once an appropriate BPM has been selected and applied to a firm's financial data base, the strategic manager has at hand an important basis for decision making. If the results are favorable, giving no indication of pending trouble, the strategist can then concentrate on improving existing operations and taking advantage of opportunities in the market place. Furthermore, strategists in such a position can use favorable BPM results to enhance their firms' standing in the eyes of investors or lenders, 
making for greater accessibility to capital markets. The strategist might also use a favorable BPM result as a basis for evaluating the impact of changes in the firm's operations or financial structure that affect the predictor variables. For instance, the impact of a heavy debt financing for new operations might be assessed by using the BPM to predict the change in, and status of, the predictor score after allowing for the expected results of the debt financing to manifest themselves. In essence, the BPM can be used as a simulation model to determine the advisability of engaging in certain actions on the basis of their impact on organizational survivability.

If the results of the BPM, when applied to current operational results, is unfavorable the signal is for management to concern itself more with finding and correcting the underlying causes rather than seeking growth or general improvement. Since BPM's have the capacity to predict problems several years in advance, an effective use of such models should provide ample time in which to avoid those problems. In addition, the longitudinal use of the model can help to evaluate the effectiveness of corrective actions by comparing a series of BPM predictor scores. If the scores show a trend toward or into favorability they indicate that the decisions being made are working as desired. If, however, the scores are unchanged or the trend is toward more unfavorable scores the indication is that the problem still exists and that further corrective action is required.

The basic importance of the BPM's to the practice of strategic management is that they provide decision makers with an additional tool with which to assess the future. As such, they can be used to signal a need for action to avoid potential problems and can serve as an evaluative tool for helping to assess the impact of major strategic decisions. If the premise that survival is fundamental to the success of business organizations is accepted, then BPM's can serve a vital function in helping to insure survival by providing timely and potentially critical information.

\section{Bankruptcy Prediction Models for External Analysis}

In addition to using BPM's to assess one's own firm, the strategic decision maker can use them to assess the financial well being of other firms. Such analysis can be of significant value in determining the relative competitive position of firms and in appraising the value and attractiveness of potential acquisitions or merger partners. If the BPM's are used to assess the bankruptcy potential of competitors the results might have an impact on planning for competitive actions. Clearly a firm showing a potential for financial problems is less likely to respond effectively to initiatives in the competitive arena. Just as clearly, a firm in a more favorable financial position than its competitors can counter the competition's moves and take actions of its own that might place substantial pressure on the competition. Therefore, BPM's can serve as a part of the basis for competitive decisions by helping to identify positions of strength to be exploited and positions of weakness to be avoided. In 
this instance the BPM is a comparative model assessing the relative financial strength of two or more firms competing in the same marketplace.

An alternate use of the BPM's in external analysis is to evaluate the present financial well being of a firm targeted for merger or acquisition and to assess the financial impact of such actions. On one hand, the BPM's may be used to seek firms showing sound financial positions as a means of adding that strength to the acquiring firm and reducing the risk of acquisition. On the other hand, BPM's can identify firms in trouble under the assumption that they might be more readily available, might require a smaller investment to acquire, and might benefit most from an infusion of capital and managerial expertise from the acquiring firm. In either case, the BPM's give important information regarding the firm or firms of interest and thereby provide a sounder basis for deciding what course of action to take, what value to place on the target firm(s), and what risk is created by pursuing the merger or acquisition.

\section{Other Uses of Bankruptcy Prediction Models}

The primary focus of this paper has been to suggest how BPM's might be used to assist strategic managers in making decisions regarding their own firms. There are, however, other potential uses of these models that are worth mentioning. Other firms can use the BPM's to evaluate us just as we can evaluate them. Given the public nature of much of the information regarding the operating results of most major corporations it is reasonable to assume that others can estimate our financial well being and long term prospects with accuracy approaching our own. This might create an added impetus to use and react to BPM's since failure to do so might give an unacceptable competitive advantage to those firms which might benefit from our troubles.

Investors can use BPM's to help their evaluation of the risks associated with a particular firm. Whether these investors take the form of subscribers to a stock issue, purchasers of stock via the various stock markets, or lenders, the information provided by the BPM's can affect their investment decision. They may use it to make the go/no-go decision, may use it to determine the type of investment, or may use it to determine the appropriate stock price/interest rate for the investment. These decisions by potential investors will have direct or indirect impact on the firm involved and serve as an additional inducement to firms to correct problems causing an unfavorable result when evaluated with a BPM.

Government regulatory agencies may use the BPM's as a part of their regulatory review of the firms they are concerned with. Such review may include an assessment of current operations and the quality of firm management, may be used to evaluate requests for rate or other changes desired by regulated firms, or may be used as a basis for requesting relief from regulatory restrictions by firms suffering from the adverse financial consequences of compliance. As with investors, BPM's can provide information to regulators that will help determine the relationship between the agency and the firm being reviewed. 
A final important user of BPM data is the employees, particularly unionized employees, of the firm being evaluated. Since employee expenses are a major cost item for almost all firms, the effect of decisions related to pending financial problems requiring cost reductions will have a significant impact on employees. With their own BPM data, employees or their union representatives can more reliably assess the accuracy of company statements regarding financial doom than if they rely solely on those statements. The union is, therefore, in a better position to bargain for the benefit of its members, to assess the risks associated with their contractual demands, and to sell to members unfavorable contracts made necessary by company inability to pay. $\mathrm{Al}$ ternatively, the results of a BPM showing little potential for bankruptcy may counter company predictions of pending problems or show that the granting of certain benefits or concessions to the union will have no impact on subsequent operational results. At the very least, BPM resuits will advise employees of the potential for insecurity in their jobs and the financial well being of their employer.

\section{Conclusion}

Researchers have developed a number of bankruptcy prediction models that serve to assess the potential for future financial problems based on today's operational results. An astute use of the information provided by such models can be of significant value to those parties who are interested in the future of a company. In particular, the use of BPM's can provide strategic decision makers with a sufficiently timely warning of potential trouble to allow for an assessment of the causes of the problem and to devise the necessary corrective action. Therefore, the routine use of a BPM as part of the firm's internal assessment process offers a substantial benefit to the organization at a negligible annual cost. The key to the effectiveness of the use of a BPM is the selection of the most appropriate model and then insuring that it is used regularly and in a proper manner. The intention here is not to recommend any particular model but to suggest that, conceptually, a BPM is a useful tool in strategic management and the various models available should be reviewed in detail by interested managers for the purpose of selecting the one which best fits their needs.

For those firms interested in using a BPM for one or more of the uses described, it is suggested that a brief review of the literature referenced will provide access to the actual procedures and techniques needed to apply the models. In some cases the model is published and available for anyone's use. In others the model is proprietary and references are given to its developers for contact on a consulting basis.

\section{References}

1. Altman, Edward I. "Financial Ratios, Discriminant Analysis and the Prediction of Corporate Bankruptcy." The Journal of Finance, Vol. 23, September 1968, pp. 589-609. 
2. "The Success of Business Failure Prediction Models-An International Survey." Journal of Banking and Finance, Vol. 8, June 1984, pp. 171-198.

3 . "Why Businesses Fail." Journal of Business Strategy, Vol. 3, September 1983, pp. 15-21.

4. Altman, Edward I., Robert G. Haldeman, and P. Narayanan. "Zeta Analysis: A New Model to Identify Bankruptcy Risk of Corporations." Journal of Banking and Finance, Vol. 1, June 1977, pp. 29-54.

5. Altman, Edward I. and Spivack, Joseph. "Predicting Bankruptcy: The Value Line Relative Financial Strength System vs. the Zeta Bankruptcy Classification Approach." Financial Analysis Journal, Vol. 39, November 1983 , pp. 60-67.

6. Argenti, J. Corporate Collapse: The Causes and Symptoms, London, UK: McGraw-Hill Book Company (UK) Ltd., 1976.

7. Barrickman, Ray E. Business Failures: Causes, Remedies, and Cures. Washington, DC: United Press of America, Inc., 1979.

8. Beaver, William H. "Altenative Accounting Measures as Predictors of Failure." The Accounting Review, Vol. 43, January 1968, pp. 113-122.

9. "Financial Ratios as Predictors of Failure." Empirical Research in Accounting: Selected Studies, Supplement to Journal of Accounting Research, Vol. 4, 1966, pp. 71-111.

10. Dambolena, Ismael G. and Khoury, Sarkis J. "Ratio Stability and Corporate Failure." The Journal of Finance, Vol. 35, September 1980, pp. 1017-1026.

11. Dun and Bradstreet Failure Record, New York: Dun and Bradstreet, Inc., 1981.

12. FitzPatrick, Paul J. "A Comparison of Ratios of Successful Industrial Enterprises With Those of Failed Firms." Certified Public Accountant, October, November, December 1932, pp. 598+.

13. Lawrence, Edward C. "Reporting Delays for Failed Firms." Journal of Accounting Research, Vol. 21, Autumn 1983, pp. 606-610.

14. Menash, Yaw M. "An Examination of the Stationarity of Multivariate Bankruptcy Prediction Models: A Methodological Study." Journal of Accounting Research, Vol. 22, Spring 1984, pp. 380-395.

15. Merwin, Charles L. "Financing Small Corporations in Five Manufacturing Industries 1926-1936." National Bureau of Economic Research, 1942, pp. $93+$. 
16. Sadd, Victor and Williams, Robert T. Causes of Commercial Bankruptcies. Washington, DC: U.S. Government Printing Office, 1932.

17. Scapens, Robert W., Robert J. Ryan, and Leslie Fletcher. "Explaining Corporate Failure: A Catastrophe Theory Approach." Journal of Business Finance and Accounting, Vol. 8, No. 1, 1981, pp. 1-25.

18. Sharma, Subhash and Mahajan, Vijay.. "Early Warning Indicators of Business Failure." Journal of Marketing, Vol. 44, Fall 1980, pp. 80-89.

19. Tamari, M. "Financial Ratios as a Measure of Forecasting Bankruptcy." Management International Review, Vol. 4, 1966, pp. $19+$.

20. Thompson, C. J. "Danger Signs of Corporate Insolvency." Financial Executive, Vol. 50, June 1982, pp. 47-51.

21. Toffler, Richard and Tisshaw, Howard. "Going, Going, Gone - Four Factors Which Predict." Accountancy, Vol. 88, March 1977, pp. 50$52+$.

22. Winaker, A. and Smith, R. F. "Changes in Financial Structure of Unsuccessful Industrial Companies." Bureau of Business Research Bulletin, University of Illinois Press, Vol. 51, 1935. 